\title{
Researching the Research Article in Cameroon English
}

\begin{abstract}
This contribution discusses three variables of structure, citation practice, and role relationships in research articles in Cameroon English, within the background of conventional practice in the discourse community. Data is taken from 40 papers published in 7 issues of 4 journals from two state universities in Cameroon; and corroborated with a similar database from three universities in Europe. Findings indicate that articles written by Cameroonian academics display a number of differences from what is known in the literature. First, more than $80 \%$ of 40 research article introductions analysed do not situate the research in the context of on-going discussion in the field; thereby ignoring an essential Move category in the CARS (Create-a-Research-Space) model (Swales 1990). Second, while in-text citations align with the general pattern of integral and non-integral, there exist subtle differences in citation language forms; with the outcome that Cameroonian authors do not often use various options within these two broad categories. Further, reader engagement and solidarity claim, which are often achieved through the use of devices such as inclusive pronouns and directives, are not common place. This downplays the role of the reader in the text - an often less coveted rhetorical practice in the discipline.
\end{abstract}

\section{Key words}

Research article; structure; citation practice; engagement; Cameroon English

\section{Introduction}

The research article is an important genre in the university (Swales 1990, 2004), and it is the chief "means by which [university] institutions legitimate knowledge, reward success, regulate admission, control membership and induct novices" (Hyland 
2009: 67). The prestige of English-medium publications is hardly debatable, and the "symbolic and cultural capital attached to what gets labelled as 'international' [publications in English] pervades academic reward systems" (Lillis and Curry 2010: 50). However, for most scholars who live and work in ESL countries with limited resources, surviving the peer-review process often associated with main stream journals in the West is challenging (cf. Gosden 1992; Canagarajah 1996, 2002; Flowerdew 2000, 2001; Salager-Meyer 1997). According to Chovanec (2012: 7), "the current situation that is marked by the dominance of the Anglo-American norm in the globalized academia is compounded by the traditionally privileged role of standard British and American English and the model position of the native speaker". Yet, university teachers need publications for internal promotions, grant applications etc.

To meet the increasing need of qualified staff in the vast-expanding university landscape in Cameroon, scholars are now being encouraged to publish in locallybased multi-disciplinary journals, some of which had been in place for decades. Although these scholars are part of the global academic community, they operate under a different social environment - one that is marked not only by limited academic resources (documentation, editorial assistance, academic networks etc.), but also by "substrate" influences of local languages and French. In addition, the peer-review process which often contributes to the final polished article shaped to the cognitive and rhetorical requirements of the genre is often less stringently pursued by most local journal editors. In this context, research papers published in local journals in the country present interesting variations in aspects of structure, form, and content, seen from the perspective of articles published in mainstream European and North American journals. This survey attempts a first-hand assessment of some of these publications. More specifically, the study discusses three variables: structure, citation practice, and role relationships in research articles in Cameroon English. Conventional (Anglo-American) academic writing practice will constitute the basis of analysis (cf. Swales 1990, 2004; Hyland 2000, 2004, Hopkins and Dudley-Evans 1988; Yang and Allison).

\section{Genre and discourse community}

The rhetorical practices that have shaped the research article have been inspired by studies in the broader context of genre analysis. Genre analysis is a class of community events commonly used by members of a given academic community who share some set of communicative purposes (Swales 1990). In other words, a genre can be seen as a specific product of a social practice which can be described and taught because of its formal characteristics (Bloor and Bloor 1993). Although scholars have characterized genre analysis in slightly different ways, there is unanimity across the board on what it entails. Bhatia (2004: 23) summarizes these commonalities in six points: (i) genres are characterized by a set of communicative purposes which can be identifiable and mutually understood by 
members of an academic or professional community; (ii) they are highly structured and conventionalized constructs, with constraints on allowable contributions; (iii) established members of particular professional community will have a much greater knowledge and understanding of the use and exploitation of genres than apprentices and outsiders; (iv) expert members of the community often exploit generic resources to express "private intentions"; (v) genres are a reflection of disciplinary and organizational cultures, and (vi) all disciplines and professional genres have integrity of their own, which is often identified with reference to a combination of textual, discursive and contextual factors.

Based on this view of genre analysis, Swales (1990) has suggested that the research article invariably follows the conventional Introduction-Method-Results-Discussion (IMRD) model, and the research article introduction follows the Create-a-Research-Space (CARS) ${ }^{1}$ model. It has to be noted that although genre studies emphasize regular patterns in texts, it does not mean that those patterns remain fixed. Rather genre will change and evolve as a result of changes in the communicative goals and rhetorical needs of a community of specialists (see Martin 1989). In EAP tradition, therefore, genres emphasize established but not necessarily "codified conventions" and embrace "style of presentation", "the order of presentation of that content", and "all the myriad rhetorical factors that affect the plausibility for the readers of the argument presented" (Dudley-Evans 1994: 219-220). Therefore, an understanding of genres and genre analysis could be seen as a much-needed step in guaranteeing success of communication in an academic setting, such as the university; and one of the steps in such an analysis, according to Bhatia (1993), is analyzing the linguistic aspects of the corpus by focusing on lexico-grammatical features, text patterns, and structural interpretations, among other things.

A professional genre, such as the research article, may only be practised in a discourse community. The concept of a discourse community is similar to Kuhn's (1970) notion of paradigm - a comprehensive theoretical model that governs both the view of reality accepted by an intellectual community and the practices of that community's discipline. According to Kuhn, a scientific community cannot practise its trade without some set of received beliefs. These beliefs form the foundation of the educational initiation that prepares and licenses the student for professional practice. It follows from this premise that, as members of defined groups engage with one another in using language, particular ways of "saying" and "doing" will emerge and become entrenched and conventionalized. Thus, "[by] engaging with others we enter into a community of shared belief or value concerning what is interesting or worth discussing and through our language choices we align ourselves with, challenge, or extend what has been said before" (Hyland 2009: 4). An essential role of a discourse community is gatekeeping. It regulates entry and guarantees integrity of the genre by setting limits on what can be said and how it should be said, and how it should be presented for it to be accepted and validated as reliable and quotable knowledge in an academic community. ${ }^{2}$ 


\section{Previous studies on the research article}

The research article has been the subject of a range of studies exploring the structure of various sections of the genre (e.g. Swales 1981; Hopkins and DudleyEvans 1988; Yang and Allison 2004), including the abstract (Mur-Dueñas 2012; Nkemleke 2010; Anderson and Maclean 1997). Textual features such as hedging (Hyland 1998; Malášková 2011), modality (Salager-Meyer 1992), personal pronouns (Hyland 2001; Pho 2008), interrogatives (Blagojević and Mišić Ilić 2012), discourse markers (Povolná 2012), and citation practices (Swales 1990; Thompson and Ye 1991; Hyland 1999a, 2000) have also been the subject of several studies in recent years. Other studies have focused on disciplinary and cross-linguistic variations within the research article (e.g. Hyland 2000, 2002; Mauranen 1993; Samraj 2002; Valero-Garces 1996; Vassileva 2000).

Much of the structurally-based investigations on the research article (notably Brett 1994; Holmes 1997; Yang and Allison 2004) have largely been based on the conventional Introduction-Method-Results-Discussion (IMRD) model proposed by Swales. On the whole, these studies reaffirm what is generally known of the research article's structure in the literature: they typically follow the IMRD pattern with allowable variations; and article's abstracts generally follow the Create-a-Research-Space (CARS) model of Swales (1990), sometimes alternating between his old four-moves model (establishing field, summarizing previous research, preparing for present research, introducing present research) and the revised three-moves model (establishing a territory, establishing a niche, occupying the niche).

An important rhetorical strategy in a research paper is citation - a manifest intertextual marker which acknowledges the presence of an antecedent authorial voice, or the attribution of propositional content to another source (see Groom 2000; Hyland 1999a). Many studies have examined citation practices in the research article (e.g. Thompson and Ye 1991; Hyland 1999a; Buckingham and Neville 1997; Thompson and Tribble 2001; Okamura 2008; Shooshtari and Jalilifar 2010) and the dissertation (Thompson 2000) written by professional and novice writers in both ESL and non-ESL texts across disciplines. These studies have shown that while use of citations varies across disciplines, integral citations are generally more frequent than non-integral citations. This trend is confirmed in Hyland's (1999a) investigation of citation practices in a corpus of 10 journal articles in 8 disciplines, and that of Thompson (2000); who uses a corpus of $8 \mathrm{PhD}$ theses from Agriculture and Food Economics. Further, Thomson and Tribble (2001) study citation practices in EAP corpora of doctorate students in Agricultural Botany and Agricultural Economics in an L1 context, by comparing their findings with those of Hyland (1999a) and Thompson (2000). This study concludes that novice writers use a limited range of citation types. Other studies of citation have focused on variation in citation language forms. For example, Thomas and Hawes (1994) analyzed citations in medical journals to map out networks of choices for reporting verbs; and to establish patterns between particular 
verb choices and the rhetorical functions of the citations.

Interaction is a strategy of academic discussion and has received considerable attention as well. Smith (1985) sees interaction (use of pronouns, directives) as an important contextual variable that determines academic text structure (cf. Myers 1989; Ivanic 1998; Tang and John 1999; Kuo 1999), and shapes global text function and audience level. The choice of a certain personal pronoun for a given context, or even the presence or non-presence of a personal pronoun in journal articles can often reveal how writers view themselves, their relationship with the readers, and the entire disciplinary community (Kuo 1999). In his analysis of manifest intertextuality in academic writing, Groom (2000) encourages writers to clearly signal when they are reporting the voice of an antecedent author or when they are expressing their own views. Personal attribution, therefore, would seem to be an important strategy for academic writers - the basic assumption being that scientific facts or knowledge are not discovered by individuals in isolation, but are established through consensus-building discourse in scientific communities (Schmied 2012).

The literature on the research article is vast. Yet, very little is known about the genre in Cameroon English. It is hoped that this first hand assessment of the genre will shed light on how Cameroonian academics write the research paper.

\section{Data and method}

Data for this study is taken from a corpus of 40 research articles published by Cameroonian academics (henceforth CamE-ARTS corpus) in 7 issues of four local peer-reviewed journals in the areas of linguistics, applied linguistics, literature, and education. ${ }^{3}$ The journals include: Annals of the Faculty of Arts, Letters and Social Sciences (ANNALS), Revue scientifique interdisciplinaire de l'École Normale Supérieure de Yaoundé (REVIEW SYLLABUS), Revue Internationale des Arts, Lettres et Sciences Social (RIALSS) and Revue pluridisciplinaire de l'Ecole Normale Supérieure de Maroua (KALIAO). These journals are run by faculties in the University of Yaoundé I and the University of Maroua. The articles were published between 2008 and 2011, and authors are university lecturers of all rank, living and working in Cameroon. In analyzing the data, references are made to a similar database of 40 research articles from 5 issues of three journals published by English departments in three European universities within the same period (henceforth ChemBP-ARTS corpus). These journals include: REAL Studies (REAL) published by the Department of English Language \& Linguistics, Chemnitz University of Technology in Germany, Discourse and Interaction (DISCOURSE) published by the Department of English Language and Literature, Faculty of Education, Masaryk University, Brno in the Czech Republic, and English Studies \& Language Teaching (E-STUDIES) published by the Department of English, Západočeská Univerzita v Plzni, in the Czech Republic. The content of the databases is presented in Table 1. 
The relevant linguistic features analyzed in this paper were not retrieved through the conventional KWIC-concordance method; rather they were manually extracted from the journals, because it was not possible to get a text version of all the journals from publishers. The journals were distributed to groups of students, with the requirement to scan through and write out full sentences in which the relevant feature(s) occurred. The task took six weeks to complete, and the sentences were thoroughly checked by other students for correspondences on the basis of page references provided. Consequently, while the number of articles and the average length of each article in pages are known, the total number of words in each corpus is not known.

Table 1. Research articles in the CamE-ARTS and ChemBP-ARTS corpora

\begin{tabular}{|c|c|c|c|}
\hline \multicolumn{2}{|c|}{ CamE-ARTS corpus } & \multicolumn{2}{|c|}{ ChemBP-ARTS corpus } \\
\hline Journal & No. of articles & Journal & No. of articles \\
\hline $\begin{array}{l}A N N A L S \\
\text { (2 Issues) }\end{array}$ & 22 & REAL (3 Issues) & 26 \\
\hline $\begin{array}{l}\text { REVIEW } \\
\text { (2 Issues) }\end{array}$ & 6 & $\begin{array}{l}\text { DISCOURSE } \\
\text { (1 Issue) }\end{array}$ & 9 \\
\hline $\begin{array}{l}\text { RIALSS } \\
\text { (1 Issue) }\end{array}$ & 6 & $\begin{array}{l}\text { E-STUDIES } \\
(1 \text { Issue })\end{array}$ & 5 \\
\hline $\begin{array}{l}\text { KALIAO } \\
\text { (2 Issues) }\end{array}$ & 6 & - & - \\
\hline \multicolumn{2}{|c|}{$\begin{array}{c}\text { Total }=40 \\
\text { Av. length of article }=13.5 \text { pages }\end{array}$} & \multicolumn{2}{|c|}{$\begin{array}{c}\text { Total }=40 \\
\text { Av. length of article }=13 \text { pages }\end{array}$} \\
\hline
\end{tabular}

For obvious reasons, I will use findings in the ChemBP-ARTS corpus to corroborate those in the Cameroonian data. First, universities in Europe have a relatively longer tradition in academic writing and publishing than universities in Cameroon. Consequently, papers published there are likely to respond to the conventions of the genre than those published in Cameroon. Second, because the reward system for "successful" publications that prevails in European universities is well established, articles are usually properly structured, edited and peer-reviewed. Third, journal impact factor is an important index for institutional and individual evaluation in most European universities; consequently, most journals here are increasingly using formalized systems for measuring academic productivity such as the inclusion of journals in the Anglophone-centre indexes. Thus, scientific rigour in manuscript preparation is often highly valued.

Data analysis, therefore, will consist in discussing relevant features in the CamE-ARTS corpus, with reference to those in the ChemBP-ARTS corpus. However, when comparison is made between the two databases, certain aspects of incompatibility between the two should be borne in mind: Articles in the ChemBP-ARTS corpus are written by scholars from 8 university departments in 
4 European countries (Germany, Czech Republic, Greece and Italy). Publications included in the CamE-ARTS corpus are from 4 departments in 2 universities in Cameroon, only. Further, the issues covered in both corpora are not entirely identical but may largely be assumed to represent academic writing practices in the two contexts.

It is worth mentioning that not all papers published in the ChemBP-ARTS corpus are conventional research papers. A few of them were conceived as research projects that were presented at the conferences. Although this in a way may be taken to be a weakness in the constitution of that corpus, it does not, in my view, invalidate the overall assessment that this investigation makes of the research article in Cameroon English.

\section{Results and discussion}

\subsection{Structure of research articles' introduction in Cameroon English}

The results of a structural classification of 40 research articles' introduction in the CamE-ARTS corpus are presented in Table 2 following Swales' (2004: 230-232) revised CARS model.

According to this model, the research article writer takes three moves to write the research article introduction: In the first move s/he establishes the general topic being discussed or delineates a "territory". Citation of some relevant literature is often expected. In the second move the writer creates a niche within the delineated territory. Lastly, s/he occupies the niche by presenting his/her side of the story. According to the statistics in Table 1, most research paper introductions in the corpus do not adhere to this model. 35 (i.e. $87.5 \%$ ) of the 40 introductions examined ignore Move 2 altogether, and 5 (i.e. $12.5 \%$ ) fail to indicate any sort of topic generalization of Move 1. Yet, these two constituent steps are often highly desirable in a research paper's introduction. Further, Move 3 Step 1 ("announcing present research descriptively and/or purposively"); another important constituent, is $60 \%$ adhered to in the Cameroonian database. To a larger extent, therefore, articles' introductions represented in this corpus make selective use of Swales' model, ignoring for the most part, some of the important steps. Granted that published texts are the most concrete realization of the social practices of academic writing (Hyland 2000), one may argue that these structural discrepancies represent a significant trend in Cameroonian local journals. (Seven papers published in the ChemBP-ARTS corpus also make topic generalizations, but these papers were not concerned with an examination of empirical data. Rather, they were presentations of new projects $\left.{ }^{4}\right)$.

To further appreciate the practice of writing introduction to research papers in Cameroon English, it is important to look at specific examples of texts. For example, text 1 and 2 below represent two interesting extremes in the database: one with as few as two constituents (text 1), and the other with as many as five constituents (text 2). 
Table 2. Structure of research articles' introductions in CamE-ARTS corpus

\begin{tabular}{|c|c|c|}
\hline Move/constituent steps & $\begin{array}{l}\text { \% of article's } \\
\text { introductions that fail } \\
\text { to meet requirement }\end{array}$ & Observation \\
\hline \multicolumn{3}{|c|}{ Move 1: Establishing a territory (citations required) } \\
\hline $\begin{array}{l}\text { topic generalizations of increasing } \\
\text { specificity }\end{array}$ & $87.5 \%(35 / 40)$ & $\begin{array}{l}\text { obligatory } \\
\text { constituents }\end{array}$ \\
\hline \multicolumn{3}{|c|}{ Move 2: Establishing a niche (citations possible) } \\
\hline Step 1A. indicating a gap or & $15 \%(6 / 40)$ & \multirow{3}{*}{$\begin{array}{l}\text { obligatory } \\
\text { constituents } \\
\text { (one of the } \\
\text { three options } \\
\text { has to be } \\
\text { present) }\end{array}$} \\
\hline Step 1B. adding to what is known & $5 \%(2 / 40)$ & \\
\hline $\begin{array}{l}\text { Step 2. (optional) positive } \\
\text { justification }\end{array}$ & $2.5 \%(1 / 40)$ & \\
\hline \multicolumn{3}{|c|}{ Move 3. Presenting the present work (citations possible) } \\
\hline $\begin{array}{l}\text { Step 1. (obligatory) announcing } \\
\text { present research descriptively and/or } \\
\text { purposively }\end{array}$ & $60 \%(24 / 40)$ & $\begin{array}{l}\text { obligatory } \\
\text { constituents }\end{array}$ \\
\hline $\begin{array}{l}\text { Step 2.* (optional) presenting } \\
\text { research questions or hypothesis }\end{array}$ & $7.5 \%(3 / 40)$ & \multirow{6}{*}{$\begin{array}{l}\text { optional } \\
\text { constituents }\end{array}$} \\
\hline $\begin{array}{l}\text { Step 3. (optional) definitional } \\
\text { clarification }\end{array}$ & $10 \%(4 / 40)$ & \\
\hline $\begin{array}{l}\text { Step 4. (optional) summarizing } \\
\text { methods }\end{array}$ & $5 \%(2 / 40)$ & \\
\hline $\begin{array}{l}\text { Step 5. (PISF)** announcing } \\
\text { principal outcomes }\end{array}$ & $(10 \%) 4 / 40$ & \\
\hline $\begin{array}{l}\text { Step 6. (PISF) stating the value of } \\
\text { the present research }\end{array}$ & - & \\
\hline $\begin{array}{l}\text { Step 7. (PISF) outlining the structure } \\
\text { of the paper }\end{array}$ & $27.5 \%(11 / 40)$ & \\
\hline
\end{tabular}

* Steps 2-4 according to Swales (2004: 232) "are not only optional but less fixed in their order of occurrence than others"

** PISF: Probable in some fields, but unlikely in others 
Text 1. Research article introduction involving two steps in two Moves in the CamE-ARTS corpus

Title of article: Official bilingualism at tertiary level in Cameroon: The case of the University of Yaoundé II (Soa)

\section{Introduction}

[Move 3 Step 1] This study examines one type of bilingual education (see Garcia 1997 for an overview of types of bilingual education) involving the use of French and English at tertiary level in Cameroon. [Move 3 Step 7] The study is broken down into six sections, entitled overview of official bilingualism in Cameroon (1), practice of bilingualism in tertiary education in Cameroon (2), research design (3), practice of bilingualism at the University of Yaoundé II (4), discussion and recommendations (5). These are considered in turn.

Source: KALIAO: Revue pluridisciplinaire de l'Ecole Normale Supérieure de Maroua (Cameroon) 2 (4), Dec. 2010, p. 194.

Text 2. Research article introduction involving five steps in two Moves in the CamE-ARTS corpus

Title of article: The English of Francophone users in Cameroon: A phonological appraisal

Introduction

[Move 3 Step 1] This paper deals with the segmental features of Francophone English, abbreviated to FrancoE. [Move 2 Step_1A] This variety of English has received very little attention over the years, unlike the L2 English of Anglophone speakers (abbreviated to CamE), which has been analysed by various researchers including Todd (1982), Massanga (1983), Mbangwana (1987), Kouega (1991,1999), Simo Bobda (1994), Simo Bobda and Chumbow (1999) etc. [Move 3 Step 3] FrancoE is a variety spoken by Cameroonian users who have had English as a compulsory school subject and a compulsory examination subject for a number of years. [Move 3 Step 4] The data come from informal discussion, tape-recorded radio and TV interviews, contributions in work sessions, political speeches and debates, question-answer sessions in theses defences, oral sessions of competitive examinations, to name only these. The framework underlying the analysis is mainly the structural theoretical frame, with occasional incursions into the error analysis approach. The reference models for analysis are both RP and the Cameroon L2 English accent, as the work is contrastive in nature. [Move 3 Step 7] The work is divided into three sections, with the first overviewing English in the Francophone educational system in Cameroon (1). This is followed in turn by an analysis of the consonantal features of FrancoE (2) and its vocalic features (3). Source: Annals of the Faculty of Arts, Letters and Social Sciences (Special Edition) June, 2008, pp. 109-110 
The author of text 1 moves directly to mention purpose of the study and concludes by indicating the structure of the research paper. The author of text 2 does not engage in any topic generalizations, i.e. what Samraj (2002) refers to as "claiming centrality either in the real world or in research". Therefore, the text appears to lack a "narrative context" (Hyland 2009: 68). Although this research article introduction indicates a gap in the research by quoting authors who have rather worked on a different aspect of the problem, such evidence of propositional warrant seems to lack strength because it is not preceded by a clear demarcation of a 'territory' as the convention requires. By ignoring an essential step like topic generalization, which must be backed by references to previous research, and preferring to include what is optional (according to the model), this research article's introduction exemplifies a structure that is only too common in the Cameroonian database. An important criterion for recognizing a text as "academic" is usually the use of clear and fairly predictable structure (Hamp-Lyons and Heasley 2006: 30). In the case of the research article introduction, this refers to the essential stages, namely Move 1 and 2, which have to be present for an introduction to be seen as meeting the expectation of the discourse community.

The figures in Table 2 above seem to suggest that there is a certain degree of innovation in the way most research articles' introductions are written by Cameroonian scholars. For example, articles' introductions do not necessarily begin with a move that establishes the general topic being discussed, with some literature to back up this generality. Rather, they may begin straight away by talking about the topic, with no literature to back-up any claim. There are 8 examples (i.e. 20\%) of such bare presentation of academic claims (text 3 below, cf. text 1 above) in the Cameroon database.

Text 3. Research article introduction with no overt reference to previous research in the CamE-ARTS corpus

Title of article: Cultural and linguistic hybridazation [sic] in Cameroon: English loanwords in Ňgèěmba ${ }^{5}$ Introduction

[Move 1 Step 1] Factor such as trade, colonisation, religion, etc. have contributed significantly to the contact between ñgeeemba and English. One of the linguistic implications of this contact is the borrowing of a multitude of lexical items from English, a language of European importation. Once integrated into the ñgee $m b a$ lexicon, the borrowed items undergo many modifications at the level of phonology, morphosyntax and semantics. [Move 3 Step 1] The present study therefore sets out to describe these processes. [Move 3 Step 7] The presentation of background of information about the ñgeeemba language (Section 1) is followed by the classification of the loan words into various domains (Section II). An analysis of the linguistic processes underlying English loanwords in ñgěĕmba (Section III) closes up the study.

Source: Revue Internationale des Arts, Lettres et Sciences Sociales (RIALSS) 1 (4), 2011, p. 240 
There are only two such examples in the ChemBP-ARTS corpus. On average, however, there are 13 references in each article in ChemBP-ARTS corpus (a detailed analysis of citations is done in the subsequent section). The average number of references for Cameroonian article introduction is 3, and up to 10 introductions in the CamE-ARTS corpus make no mention of previous research. Quoting existing studies in the area to back one's generalization is a mandatory process in crafting an academic text, which according to Hyland (2009: 68) "indicates that facts are not just added piecemeal to the heap of existing knowledge, but are the extension of an on-going conversation among members, conducted in a shared theory-laden language and particular pattern of argumentation". This means that any potential contribution to knowledge, therefore, may only be assessed considering the extent to which present propositions are based on previous claims.

\subsection{Citation practices}

Table 3 presents the total number of citations in the introduction and discussion sections of research articles in the CamE-ARTS corpus, following Swales' (1990: 148) model of integral (citation outside the brackets) and non-integral (citations inside the brackets).

Table 3. Frequency and citation types in the introduction and discussion sections of research articles in CamE-ARTS and ChemBP-ARTS corpora, compared

\begin{tabular}{|l|c|c|c|c|}
\hline \multicolumn{1}{|c|}{ Database } & $\begin{array}{c}\text { No. of } \\
\text { articles }\end{array}$ & $\begin{array}{c}\text { Total } \\
\text { citations }\end{array}$ & Integral & Non-integral \\
\hline $\begin{array}{l}\text { CamE-ARTS } \\
\text { corpus }\end{array}$ & 40 & $250(100 \%)$ & $136(54.4 \%)$ & $114(45.6 \%)$ \\
\hline $\begin{array}{l}\text { ChemBP-ARTS } \\
\text { corpus }\end{array}$ & 40 & $513(100 \%)$ & $157(30.6 \%)$ & $356(69.4 \%)$ \\
\hline
\end{tabular}

The introduction and discussion sections are the central focus here because they usually take a broad view, relating what is known in the field at large, as opposed to the methods and results sections that are narrow, and focus on the research itself (cf. Hill et al. 1982; Hanania and Akhtar 1985). The introduction and discussion sections are, therefore, those sections in which the use of citations is most warranted. In quantitative terms, citations are far less frequent in the articles written by Cameroonian scholars. The average paper in the CamE-ARTS corpus has 6 citations. This figure is comparatively low compared to the ChemBP-ARTS corpus, with an average of 13 citations per paper. Furthermore, 10 introduction sections (i.e. 25\%) (cf. text 3 above as example), as well as 12 discussion sections of articles in the CamE-ARTS corpus have no citations. Less than 5 research articles in the ChemBP-ARTS corpus have no citations in the introduction section, and 3 others have no citations in the discussion section. 
One way of assessing citation use in academic text is quantitative (see Cole 2000): the number of citations is used as a criterion to judge the importance of the work within the discipline, though this is debatable. Granted that writers cite authors for various reasons, including persuasion and merit-granting (cf. Davenport and Cronin 2000; Brooks 1984; Latour 1987; Case and Higgins 2000), a strong correlation between citation density and quality may be assumed; since, as Shim (2005) observes, research is essentially cumulative, and the texts cited are the foundation on which new research is built and are chosen because of their high quality. Furthermore, to a large extent, research is organized on a subject or disciplinary basis, i.e., researchers build on previous research conducted within the discipline. On the basis of the citation density criterion, therefore, we may observe that the papers published in local Cameroonian journals do not show the same degree of scholarship when compared to those written by their European counterparts.

With respect to integral and non-integral citation, there is a slightly higher preference for the former in the CamE-ARTS corpus $(54.4 \%$ vs. $30.6 \%$ in the ChemBP-ARTS corpus) as in examples $1-4^{6}$.

(1) For Towa (1985:24) quoted by Menang (2001: 7), identity is what permits us to single one thing out of many and can be described using criteria which constitute a number of features [sic] (CamE-ARTS corpus: Annals 1 (13), 2011, p. 129)

(2) Margo Gothlieb and Ngoc Dien Nyuyen (2005: 935) hold that bilingual language education, the use of two languages as the medium of instruction for two distinct student population [...] (CamE-ARTS corpus: KALIAO 3 (5), 2011, p. 152)

(3) Previous studies such as Kouega (1999), Anchimbe (2007) and Mforteh (2007) have diligently studied attitudes and perceptions of Cameroonians in relation to the two colonial languages (CamE-ARTS corpus: RIALLS 1 (4), 2011, p. 110)

(4) In this regard, Ngeh (2006) and Amonbi (2008) demonstrated that most universities and secondary schools have integrated ICTs and are already using them as instructional devices (CamE-ARTS corpus: Review 2 (1), 2010, p. 158)

This contrasts sharply with the figures in the ChemBP-ARTS corpus, where there is a very strong preference for the use of non-integral citations ( $69.6 \%$ vs. $30.6 \%)$. In other words, non-integral citations occur $199(39 \%)$ times more than integral citations in the ChemBP-ARTS corpus. In the CamE-ARTS corpus, there are only $22(9 \%)$ times more non-integral citations used than integral citations. This is an interesting contrast, which texts 4 and 5 further exemplify [all emphases are 
mine]. Both texts are examples with the highest number of citations in the two corpora. But while the Cameroonian text exclusively uses integral citations, the ChemBP-ARTS corpus text exclusively uses non-integral citations.

Text 4. Research article introduction in the CamE-ARTS corpus with the highest number of citations (i.e. 17)

Title of article: Further Development in Cameroon Pidgin English (CPE) Introduction

Although serious scholarship on CPE would have started only in the early 1960s with scholars of the calibre of Schneider $(\mathbf{1 9 6 3}, \mathbf{1 9 6 6})$ and through the 1970s to the present with Mbassi-Manga (1973), Todd (1974, 1979, 1990), Menang (1979), and Ngome (1982), it can be said without fear of contradiction that it is Mbangwana $(\mathbf{1 9 8 3 , 1 9 9 1 , 2 0 0 4 )}$ along with his colleagues and many students in the example of Ayafor (1996, 2000, 2004, 2006) and kouega (2001), Abangma (2008) etc. who the most has [sic] left an indelible stamp of worth and credibility on CPE both as an indispensible communication tool in the building of a linguistically heterogeneous Cameroon nation and as a worthy scientific pursuit. As it could easily be gleaned from titles furnished by these scholars, the origin, sound system, lexicon, syntax, semantics, status, scope and role of CPE etc. have been studied pretty exhaustively. However, since CPE is a living and dynamic language we should expect developments in perpetuity for, as Wilhelm von Humboldt has noted (1836 cited in Jean Atchison (1981:14): there can never be a moment of truce standstill in language, just as little as in the ceaselessly flaming thought of men. By nature, it is a continuous process of development [...]. Indeed these developments are abundant in CPE; it only takes a keen and interested observer to find them. In the first part of this paper a few significant developments on the corpus of CPE will be described. Later on in the second, part, focus will turn to the scope and role of CPE.

Source: Annals of the Faculty of Arts, Letters and Social Sciences. Special edition, 2008, pp. 39-40.

Text 5. Research article Introduction in the ChemB-ARTS corpus with the highest number of citations (i.e. 27 citations)

\section{Title of article: Content and Wording of Academic Course Descriptions} Introduction

Academic discourse studies mainly comprise three research domains: analysis of how scholars represent, validate and disseminate their research findings (e.g. Swales 1990, Bhatia 1993, Myers 2000, Bondi 2004, Diani 2004, Rőmer 2005, Soler 2007, D'Angelo 2009, Grazzi 2009), examination of how novices are socialized into the interactional practices of academic communities (e.g. Swales \& Feak 1994/2004, 2000, Tognini-Bonelli \& Del 
Lungo Camiciotti 2005, Hyland \& Bondi 2006, Flottum, Dahl \& Kinn 2006, Bruce 2008, Gotti 2009, Hyland 2009, Hyland \& Diani 2009), and also description of how academics develop communicative practices in handling professional and social relationships, and in carrying out administrative tasks (e.g. Swales 1988, Fairclough 1993, Räisänen 1999, Trix \& Psenka 2003, Giannoni 2006, Gesuato 2008, Gea Valor \& Inigo Ros 2009, Bernardini, Ferraresi \& Gaspari 2009). This paper is meant to contribute to the third above-mentioned line of research by examining academic course descriptions (ACDs). These texts qualify as a hybrid institutional genre, partly housekeeping and partly gatekeeping (Srikant Sarangi, personal communication 2009). They serve two communicative purposes: a logistical-informational one (i.e. conveying information to prospective attendees about the contents and structure of courses) and a pedagogicalregulatory one (i.e. imposing requirements that regulate access to and participation in courses). The analysis focuses on how content, structure and wording of ACDs are influenced by their twofold goal, partly orientation and partly directive.

Source: Research in English and Applied Linguistics, REAL 5, Göttingen: Cuvillier, 2011, pp. 79-80

The choice between integral and non-integral citation carries important rhetorical implications in academic writing, not least because the one (i.e. the non-integral type) is conducive to the free flow of textual argument, since the citations are backgrounded in the brackets. Cameroonian authors, who place citations in the subject position, for example, seem to pay more attention to the structure of the citations; while the use of non-integral citations (as in the ChemBP-ARTS corpus) rather places an emphasis on the function of the citations. The form-function dichotomy is a relevant one in the literature of citation use in ESL contexts, where it has been reported that non-native writers tend to overuse integral citations (Thompson and Tribble 2000; Shooshtari and Jalilifar 2010; cf. Pickard 1995). Assuming, therefore, that the two texts represent the prototype of citation density in both contexts, it can easily be seen that text 5 exemplifies a more crafted and sophisticated line of argument than text 4 . Consequently, text 5 appears to be more persuasive than text 4 . A further analysis of the corpus of articles written by Cameroonian scholars reveals that up to 10 of the 40 research article introductions investigated have no citations at all. Research is largely part of the collective activity of knowledge construction in the discourse community, i.e., researchers build on previous research conducted within their fields (Shim 2005). From this perspective, a research article introduction, which does not allude to previous knowledge claim, cannot possibly make a reliable contribution to on-going knowledge and debate in the discipline. To the extent that the article introductions, represented in the CamE-ARTS corpus, reflect general tendencies in the writing of this genre in Cameroon English, we may conclude that the research papers written by these scholars would hardly pass the quality assessment test of journals published in Western countries. 
It has been noted that variation in citation language forms is a mark of authentic academic text (see Buckingham and Nevile 1997), not least because the forms within the integral and non-integral citations often reflect useful choices in the construction of such text. The frequency of these citation forms in the CamEARTS corpus is presented in Table 4, with comparable figures from the ChemBPARTS corpus, and commented upon below.

Table 4. Forms of integral and non-integral citations in the CamE-ARTS and ChemBP-ARTS corpora

\begin{tabular}{|l|l|c|c|}
\hline \multirow{2}{*}{$\begin{array}{c}\text { Citation } \\
\text { types }\end{array}$} & sub-categories & CamE-ARTS corpus & ChemBP-ARTS corpus \\
\hline \multirow{4}{*}{$\begin{array}{l}\text { Integral } \\
\text { citations }\end{array}$} & verb-controlling & 52 & 112 \\
\cline { 2 - 4 } & naming & 133 & 131 \\
\cline { 2 - 4 } & non-citation & 1 & 5 \\
\cline { 2 - 4 } & Sub-total & $\mathbf{1 8 6}$ & $\mathbf{2 4 8}$ \\
\hline \multirow{4}{*}{$\begin{array}{l}\text { Non-integral } \\
\text { citations }\end{array}$} & source & - & 115 \\
\cline { 2 - 4 } & identification & 15 & 135 \\
\cline { 2 - 4 } & reference & 49 & 7 \\
\cline { 2 - 4 } & origin & - & $\mathbf{2 6 5}$ \\
\cline { 2 - 4 } & Sub-total & $\mathbf{6 4}$ & $\mathbf{5 1 3}$ \\
\hline Total & & $\mathbf{2 5 0}$ & \\
\hline
\end{tabular}

Verb-controlling: the citation acts as the agent that controls a verb, in active or passive voice

(5) Anchimbe (2007: 3) joins Makoni and Meinhof (2003: 1) to affirm that intertribal marriages, the random displacement of slaves for slave trade and slavery, migration [...] made many Africans and Asian contexts heavily multilingual before the era of colonisation (CamE-ARTS corpus: RIALLS 1(4), 2011, pp. 111-112)

(6) This trap had already been pointed out much earlier by Jikong and Koenig (1983: 77) when they observed that language usage and language preference are not necessarily compatible in Cameroon and in the case of Pidgin English are apparently contradictory (CamE-ARTS corpus: Annals, Special Issue, 2008, p. 44)

Naming: the citation is a noun phrase or part of a noun phrase

(7) Concerning the thematic grouping of lexical items in Camfranglais, Kouega (2003a) as quoted by Kouega (2003b: 512), notes that the most frequent issues discussed by adolescents who speak Camfranglais include food and 
drinks, money and ways of laying hand on it [...] (CamE-ARTS corpus: Annals 1 (13), 2011, p. 131)

(8) However, Mentah (2000:36) in citing Chumbow holds that the latter attempts to find reasons for the slowdown in development of institutional bilingualism (CamE-ARTS corpus: KALIAO 3 (5), 2011, p. 156)

Identification: the citation identifies an agent within the sentence it refers to

(9) The secret of this language was penetrated during the compilation of two dictionaries - one of Cameroon English (Kouega 2007a) and the other, of Cameroon Pidgin English (Kouega 2008a). (CamE-ARTS corpus: Review 1 (1), 2010, p. 89)

(10) As will be shown below, empirical indicates that there are differences between males and females in the roles they play in classroom interactive patterns (Benor et al. 2002; Cameron and Kulick 2003 and Eckert 2000) (CamE-ARTS corpus: Annals, Special Issue, 2008, p. 153)

Reference: this is usually signal by the inclusion of the directive verb "see"

(11) However, it is generally admitted that the first contact that Cameroon had with the Western world was with the Portuguese (see for example Mveng, 1963; Le Vine, 1964; Fanso, 1975) (CamE-ARTS corpus: Annals, Special Issue, 2008, p. 63)

(12) Most Bantu languages have an SVO order (cf. Watters 1989; Mchombo 2004). (CamE-ARTS corpus: RIALLS 1 (4), 2011, p. 168)

The first remark to make on the occurrences of the sub-categories of citations forms by Cameroonian scholars is their overall under-representation vis-à-vis the articles written by their European colleagues (cf. graphic presentation in Figure 1). Second, there is a certain degree of "specialisation" in the use of the subcategories of citation forms in the CamE-ARTS corpus. That is, there is tendency for one particular form to occur more than other alternatives. For example, while the naming-type occurs 133 times, the verb-controlling-type occurs only 52 times, giving a differential frequency of 81 . Although the naming-type also occurs slightly more frequent than the verb-controlling-type in the ChemBP-ARTS corpus, the frequency gap is only 19. The same trend is true of the top most frequent forms in the non-integral citation category, identification and reference. Here again figures for the CamE-ARTS corpus are skewed in favour of reference, with more than $75 \%$ of them employing the form "cf." and "e.g." rather than the prototypical directive verb, "see". 
Figure 1. Graphic representation of citation forms in the CamE-ARTS and ChemBP-ARTS corpora

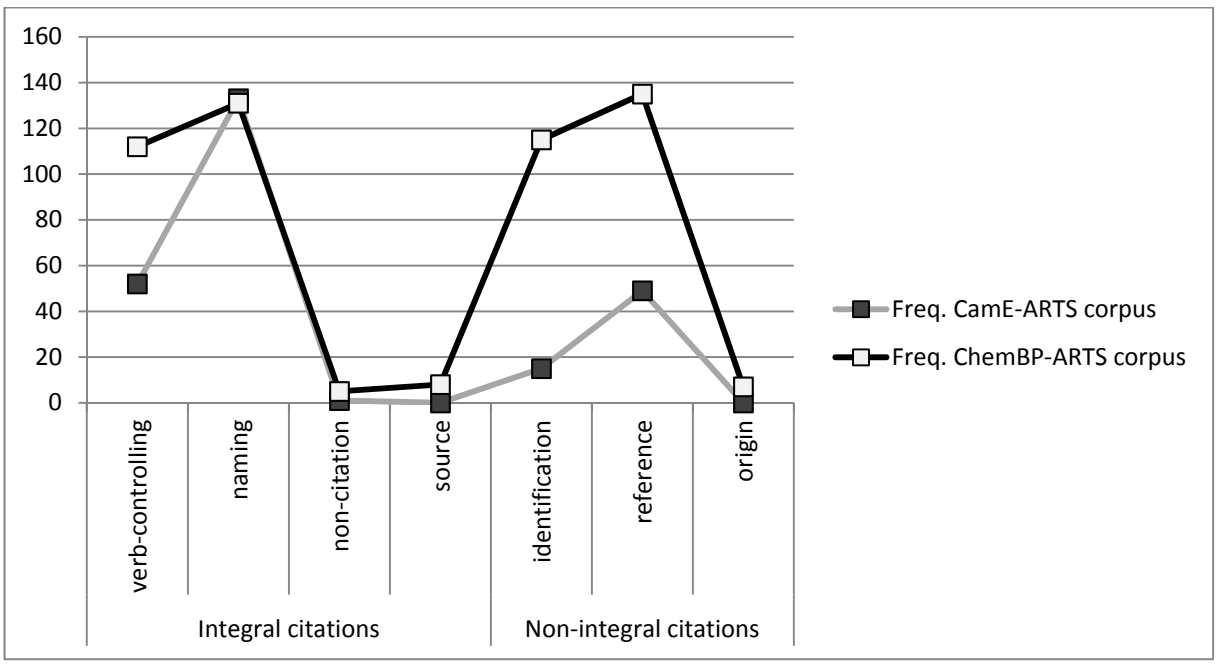

Among the forms of integral and non-integral citations above, the verb-controlling type has been singled out as an important indicator of experienced academic writing style. This is because of the different levels of "controversy" and "engagement" implied in the choice of verbs employed in the citations (cf. Thompson and Hunston 2001). In their model of citation options, Buckingham and Nevile (1997: $53 \mathrm{ff}$ ) make reference to the notion of controversy and engagement. The former represents points of potential or actual difference between colloquy ${ }^{7}$ members: knowledge is presented as negotiated ("negotiable") or challenged ("challengeable"). These options may be inferred in the choices of verbs used: i.e. do they reflect connotation, affect or attitude (see Thompson and Hunston 2001: 1-6). Affect or attitude means a critical academic attitude of doubt or challenge - "a writer controls the text's engagement with the colloquy, and also the reader's sense of engagement with both the colloquy and the writer's text" (Buckingham and Nevile 1997: 54). To assess how Cameroonian scholars' texts engage the reader with knowledge, I use the examples of the following verbs in the verb-controlling category above, in Table 5, with textual examples following after. In the first place, the number of citations that involved reporting verbs in the Cameroonian database is slightly less than $50 \%$ of the same occurrences in the ChemBP-ARTS corpus (compare 55 to 112). 
Table 5. Frequency and types of verb-controlling citations in the CamE-ARTS corpus

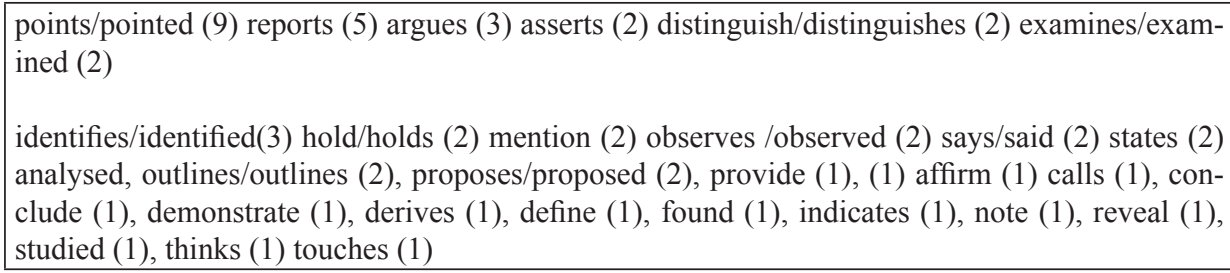

On the basis of these frequencies, we can infer that the number of instances in which Cameroonian scholars take stance in the cited author's knowledge claim is less frequent. This also implies that reader engagement in inter-textual reflection is not common.

(13) As Bamiro (1994: 54) points out, in non-native contexts, translation equivalents can either be due to interference, constant relexification of home languages, inadequate exposures of speaker's to "exonormative models" i.e. native models (Kachru, 1986:21). (CamE-ARTS corpus: Annals 1 (13), 2011, p. 141)

(14) McArthur (2002: 364-4) reports that, of some 40 newspapers, only two are English medium: the South China Morning Post and the Hong Kong Standards (CamE-ARTS corpus: Review 1 (1), 2010, p. 47)

(15) As an alternative, Kouega (2005) proposes that OL2 [official language 2] teachers be trained in sufficient numbers for secondary schools, where they will take content-oriented OL2 language lessons (CamE-ARTS corpus: KALIAO 3 (5), 2011, p. 156)

(16) Mbassi-Manga (1976: 62) argues that Cameroon Educated English (CEE) and Cameroon Pidgin English overlap in varying degrees of intelligibility (CamE-ARTS corpus: Annals, Special Issue, 2008, p. 77)

The first two examples involve "denotational verbs" (Buckingham and Nevile 1997: 56), "points" and "reports", which do not indicate writer's evaluation of the content of the proposition of knowledge claim. They also happen to be the most frequent reporting verbs in the Cameroonian corpus. These examples can be tagged in the following manner: (i) knowledge is accepted, (ii) there is no controversy, and (iii) there is no reader engagement. ${ }^{8}$ The last two examples involve the stance or evaluation verbs, "proposes" and "argues". They evoke some kind of controversy and reader's engagement. In these cases, the knowledge claimed may be contested and so it is negotiable. Among the first top 10 reporting verbs in the ChemBP-ARTS corpus, 4 stance and evaluation verbs occur with a total 
frequency of 41 distributed across 23 (i.e. $58 \%$ ) of the 40 research articles investigated. These verbs include: "suggest" (17 times), "show" (13 times), "claim" (8 times), "argue" (3 times). They represent more than 50\% of the occurrences of reporting verbs in the ChemBP-ARTS corpus. Furthermore, in terms of representation of reporting verbs in research articles in the CamE-ARTS corpus, less than 10 of the 40 research articles investigated have over $80 \%$ of reporting verbs. In other words, very few authors use citations with reporting verbs; and among those few there are two articles with relatively high figures of reporting verbs, i.e. 6 and 7. The highest number of reporting verb per paper in the ChemBP-ARTS corpus is 4. In general, reporting verbs appear to be more evenly spread across research articles in the ChemBP-ARTS corpus (compare the databases in Figure 2) than in the CamE-ARTS corpus.

Figure 2. Distribution of reporting verbs across research articles in the CamEARTS corpus and the ChemBP-ARTS corpus

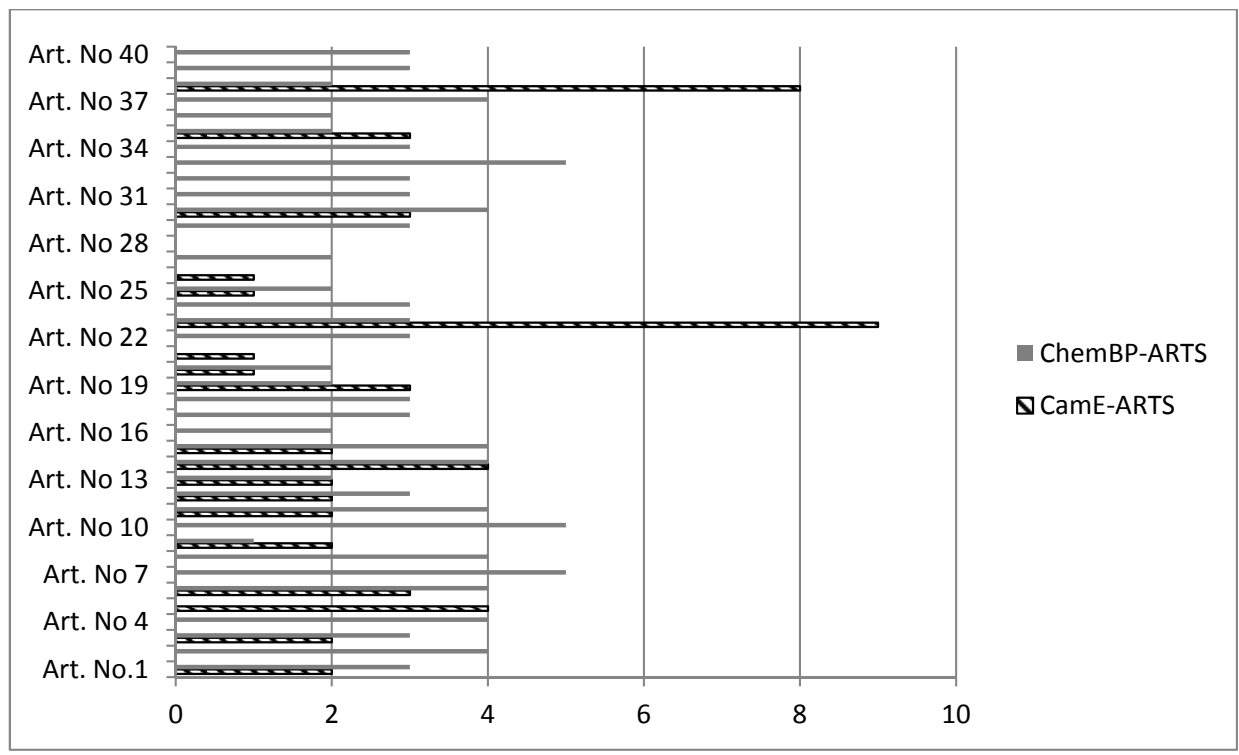

The important point about the use of reporting verbs in citations, especially those that encode writer stance/evaluation, is that "every argumentative academic text must [necessarily] present some knowledge as negotiable in order for new knowledge, the writer's contribution, to arise" (Buckingham and Nevile 1997: 57). In view of the relative infrequency of stance/evaluation verbs in the CamE-ARTS corpus, it may be speculated that Cameroonian scholars do not focus on controversy as often as their European counterparts do. Consequently, their research findings may be seen to lack legitimacy, since real reader engagement and controversy, which are sustained by stance verbs, is the lead-up to new knowledge creation, and eventually acceptance and validation. 


\subsection{Exploring role relationships in text}

In the construction of academic discourse, a writer may basically assume two roles. First, he/she may choose to engage in unmediated discourse, where the exclusive $1^{\text {st }}$ person singular $(I, m e$ and $m y)$ are predominantly used to mark a strong sense of authorial presence. Second, he/she may choose to mediate his/her claims; in which case, interaction markers such as the inclusive $1^{\text {st }}$ person plural pronouns (we, us, our) may be used, including directives (e.g. let us consider, it is important). This means that in the course of crafting an academic paper, the expert writer may switch roles: at one time he/she may act as a mediator of knowledge claim (i.e. engages the reader/the research community), and at another time he/ she may act as a creator of knowledge (i.e. prescribes, as it were). The choice of one or the other can reveal how writers view themselves and their relationship with the readers, and even the discourse community. This section examines both uses. Table 6 presents the overall frequency of these forms ${ }^{9}$ in the CamE-ARTS corpus, with comparable figures from the ChemBP-ARTS corpus.

Overall, pronouns and directives are less frequently used by Cameroonian authors. For example, the 1st person singular pronouns, $I, m e$ and $m y$ are four times more frequent in the ChemBP-ARTS corpus than in the Cameroonian database. Two interpretations are possible here: First, these forms mark a strong authorial presence in texts. Consequently, it might be speculated that avoidance of them in Cameroon English reflects a more cautious attempt by Cameroonian authors to avoid personal intrusion in their text. The second interpretation is that since these forms mark a strong authorial presence, most Cameroonian authors do not feel they have enough credentials to advance unmediated claims. On the other hand, the use of "I", especially, is also a mark of reflexive style - one that portrays the researcher himself as engaged in some kind of process, and enables her/him to share insight with the reader on why/how s/he undertook a certain task (examples 17-19) or how s/he will proceed (examples 20-21) in a certain direction.

(17) As a source of the examples for the practical part of the thesis, a series of information leaflets about the city of Plzeň was chosen. Originally, I had intended to focus on the wider range of Plzeň-based English text, e.g. hotel leaflets, the bilingual stickers appearing on Plzeň city transport vehicles, signs to customers in shops and hypermarkets etc. (ChemBP-ARTS corpus: E-STUDIES, p. 55)

(18) For better orientation in my Master thesis, the examples were divided into several groups according to their characteristics. [...] For reasons of space, I have selected just a few examples of each of these to present in this paper. (ChemBP-ARTS corpus: E-STUDIES, p. 59)

(19) In this article, I have drawn upon the following theories: the theories of politeness [...]. My interpretation of politeness devices that occur during 
doctor-patient interaction draws from [...] (ChemBP-ARTS corpus: DISCOURSE p. 68)

(20) [...] Even with their contrasting background, I will argue both Lawrence and Soyinka imagine a possible confluence for the expression of colonial postindependence identity. (CamE-ARTS corpus: Annals, Special Issue, 2008, p. 117)

(21) [...] especially when the first world war had called a lot of these values into question, Green's work following on these lines to me is the types of questions they raise about the fundamental truth of Christian morality which to him contradicts sharply with the very nature of humans (CamE-ARTS corpus: KALIAO 2 (4), 2010, p. 47)

Examples such as 17-19 above are rarely used by Cameroonian authors. A total of $81^{\text {st }}$ person singular pronouns occur in the CamE-ARTS corpus (Table 6).

Table 6. Overall frequency of pronouns and directives in the CamE-ARTS and ChemBP-ARTS corpora

\begin{tabular}{|l|c|c|}
\hline Forms & CamE-ARTS corpus & ChemBP-ARTS corpus \\
\hline $\begin{array}{l}1^{\text {st }} \text { person singular } \\
\text { pronouns (total) }\end{array}$ & $(8)$ & $(45)$ \\
\hline$I$ & 7 & 34 \\
\hline$m e$ & 1 & 3 \\
\hline$m y$ & - & 8 \\
\hline $\begin{array}{l}1^{\text {st }} \text { person plural pronouns } \\
\text { (total) }\end{array}$ & $(69)$ & $(86)$ \\
\hline we & 31 & 61 \\
\hline us & 17 & 11 \\
\hline our & 21 & 14 \\
\hline Directives (total) & $(31)$ & $(98)$ \\
\hline$c f .$, see, see for example & 31 & 98 \\
\hline Total & $\mathbf{1 0 8}$ & $\mathbf{2 2 9}$ \\
\hline
\end{tabular}

There are up to 45 occurrences of the same forms in the ChemBP-ARTS corpus; many of which are used to describe the writer's role/experience in the research process exemplified by examples 17-19 above. Although the use of these pronouns also depends on the nature of the research/methodology, in many ways, their occurrences show a greater acknowledgment of the role of the researcher in the research process; and may be seen as a powerful form of proof or evidence in academic writing. It would seem Cameroonian scholars have adequately internalised the old handbook rule which often discourages the use of 'I' in formal 
writing. In general, greater acknowledgement of the presence of the researcher in their work is increasingly prevalent in academic writing (cf. Harwood 2005a, 2005b; Harwood and Hadley 2004; Fløttum et al. 2006). According to Brown and Yule (1983: 1), academic writing not only serves a transactional function (i.e. the function in which language serves the purpose of content expression), but it also serves an interactional function (i.e. dealing with the expression of social relations and personal attitudes).

First person plural pronouns (we, us, and our), including directives ( $c f$. , see, for example) are interaction markers. Hyland (2005) refers to them as "engagement" features. They alert the reader to the author's perspective towards both the propositional information and the readers themselves, thus contributing to a reader-writer relationship. Such a relationship defines the modern scientific article, which has to associate the reader and the wider scientific community into the on-going discussion. This association is considered not only as a mark of politeness, but also as an essential conventional requirement of the discipline. ${ }^{10}$ These inclusive pronouns and directives occur twice as many times in the ChemBPARTS corpus than in the CamE-ARTS corpus. This indicates that there appears to be much more interaction (i.e. writer engages reader/writer directs reader to specific sources or examples in and out of the text) going on in the texts written by foreign scholars than there is in those written by Cameroonian scholars. Some of these role relationships can be illustrated with the following examples: (i) weinclusive (examples 22 and 23) and our/we-exclusive (e.g. example 24).

(22) Complexity and coherence in language can be considered on different levels; linguistically, we can distinguish three levels of description beginning with morphology and walking upward to semantics and pragmatics [...] This means that the morphological causative has a bi-clausal d-structure in which the lower verb node undergoes syntactic (head-in-head) movement (cf. Baker 1988) (ChemBP-ARTS corpus: REAL Studies 3, p. 2)

(23) That particular movement and the manner in which he takes the brandy reveal both a sense of duty and resignation. We are told that he took a long look at it, with eyes on the impassive child, the baked street, the vultures moving in the sky like indigestion sports [...]. The absorption of a particular movement is tendentious as we are told that "he was shaken by a tiny rage and immediately asked for his brandy..." (CamE-ARTS corpus: KALIAO 2 (4), 2011, p. 63)

(24) Our analysis shows diphthongization on the dominant restructuring pattern for RP fricatives in CamE [...]. The token we used to test the restructuring of the adjacent RP segments in CamE exhibited a rather spelling pronunciation pattern. (CamE-ARTS corpus: RIALLS 1 (4), 2011, p. 203)

Predominantly, the exclusive function of these pronouns is more frequent in the CamE-ARTS corpus: for example, out of the 69 occurrences of we, our, and $u s$ in 
Table 6 above, less than half have an inclusive reference; while the distribution between inclusive and exclusive reference appears to be skewed in the ChemBPARTS corpus in favour of inclusive reference. Furthermore, up to 12 cases of inclusive $w e$ in the Cameroonian databases (as in example 24) are from one author and the article is a literary one. In view of its repeated use in one text, we may see it as characterizing the individual author rather than as a reflection of a conscious engagement strategy.

There is also a greater intertextual cross-referencing in the text found in the ChemBP-ARTS corpus than in the CamE-ARTS corpus. For example, the directives: see, see for example, and $c f$. are relational elements, which often contribute to the text's level of engagement or detachment (Hyland 1999b; cf. Breeze 2007). They direct the reader to look elsewhere for information, explanation etc. that is useful for the present contextual purpose. In this way, an academic text is seen as a forum in which the writer, the reader, and the research community interact and socialized. With a frequency figure of 98 , the occurrences of these relational features in the ChemBP-ARTS corpus are three times more frequent than their occurrences in the CamE-ARTS corpus (cf. Table 6). Two possible interpretations might account for this. The first is that most Cameroonian authors still basically subscribe to the distant and impersonal view of academic writing, which sees scholarly texts as largely unmediated: the researcher tells the reader about his/ her research and findings and does not engage the reader in any way. Second, it is possible that most Cameroonian authors are simply not used to the rhetorical options available for crafting academic texts. Most Cameroonian libraries do not subscribe to academic journals, and in my experience working in Cameroon, a majority of the colleagues I know do not subscribe to journals, either.

\section{Conclusion}

The preceding discussion has attempted to scrutinize the research paper genre in Cameroon English, on the basis of community practices. From the structural perspective, articles written by Cameroonian academics show significant structural differences from the Create-a-Research-Space (CARS) model of Swales (1990). For example, the study found out that more than $80 \%$ of the 40 research articles' introductions analyzed fail to situate the research in the context of on-going debate in the field. In other words, these research articles' introductions did not make use of topic generalisation of any sort (cf. Table 2). This is an essential step in the research paper, one that puts the author and his/her research at the position where a contribution to knowledge can be made. Furthermore, $60 \%$ of the papers fail to explicitly announce the purpose of their present research, another important step in framing a research article. The picture is not different with respect to citations. The average paper in the Cameroonian database has 6 references; this represents less than half of cited references in the average article written by academics in the European universities investigated. Citation density, as dis- 
cussed earlier, may lend credibility to research and to the author to some extent (Cole 2000), and contributes to overall textual function of the research paper as a piece of persuasive discourse (Davenport and Cronin 2000; Case and Higgins 2000). On the basis of these requirements, we can conclude that Cameroonian research papers, viewed in the context of papers published in foreign journals, tend to move away from the Anglo-American standard practice to a larger extent. The issue of how writers-researchers position themselves in the text and how they perceive their relationship with readers has also been explored. The trend indicates that Cameroonian authors do use engagement (inclusive pronouns and directives) features to seek solidarity and approval of their academic colleagues, and occasionally indulge in subjectivity by using exclusive $1^{\text {st }}$ person pronouns. However, the extent to which these roles are frequently visible is relatively low. For example, interaction markers, which are used to engage and seek reader's solidarity, occur twice as many times in the ChemBP-ARTS corpus than in the CamE-ARTS corpus. In many ways, therefore, the research paper in Cameroon English appears to exhibit interesting differences, viewed from the perspective of the conventional research paper.

English academic writing promotes an Anglo-American model. However, findings in this survey provides evidence and justification, as many others (see Lorés-Sanz 2012), for pursuing research on "other" academic norms in ESL communities. However, determining legitimate local norms for scholarly writings could be practically daunting. It is hoped that the present study will contribute to the on-going debate on academic writing norms in cultures (cf. Chamonikolasová et al. 2012).

\section{Notes}

1 The CARS model has subsequently been revised in Swales (2004: 230-232), and it is this revised version (cf. Table 2) that is used in this study.

2 Note, however, that the notion of discourse community does not necessarily imply homogeneity of practice across a research community, or what Blommaert (2006) refers to as a "horizontal metaphor", not least because generic conventions themselves are far from static. Some scholars (e.g. Lillis and Curry 2010) have emphasized the need for a vertical dimension, citing potential differences that might occur in academic writing in the same discipline.

3 I am thankful to my 4th year students of the Department of English at the Ecole Normale Supérieure (2012/2013), for their assistance with manual-data-retrieval from the corpora of journal articles, without which this study would not have been realized.

The REAL Series volume in which these papers appeared was about English Projects in Central Europe.

5 This is a Bantu language spoken in Cameroon.

6 Examples 1 and 2 are unique because they are not also written following standard practice.

7 Buckingham and Nevile (1997: 53) pointed out that academic writers place a value on citations which reflect a number of assumptions, including the idea that knowledge arises from a dynamic system of research, analysis and communication (cf. Becher 1989). Based on this assumption, the academic world consists of individuals, who are constantly researching, 
analysing, and communicating with each other within a complex multi-member colloquy in which any cited author's 'studying', 'finding', arguing' etc. must always occur in the context of other author's 'studying' etc. They concluded that any act of citation necessarily brings this colloquy into being: the moment a writer cites, the colloquy exists. For details on this code glosses see Buckingham and Nevile (1997).

9 There are many types of directives markers. However, the choice of the forms presented here was dictated by their occurrence in the text. None of the journals used for this study has a stated editorial policy about the use of personal pronouns.

The convention referred to here is a reflection of the evolution of the scientific paper after the 19 century, where the focus gradually shifted to the method of investigation, results and findings. As Bazerman (1994: 170) observes, "the finding or theory has increasingly been brought into the central grammatical position, while the publishing scientists have been given a back seat".

\section{Acknowledgement}

I wish to thank the two anonymous reviewers, whose suggestions have been helpful in preparing the final version of this paper.

\section{References}

Anderson, Karen and Maclean, John (1997) "A genre analysis study of 80 medical abstracts". Edinburgh Working Papers in Applied Linguistics 8, 1-23.

Bazerman, Charles (1994) Systems of genres and the enactment of social intentions. In A. Freedman and P. Medway (eds.) Genre and the new rhetoric. London: Taylor \& Francis, 83-96.

Becher, Tony (1989) Academic Tribes and Territories: Intellectual Enquiry and the Culture of Disciplines. Milton Keynes: Open University Press.

Bhatia, Vijay K. (1993) Analysing Genre: Language Used in Professional Settings. London: Longman.

Bhatia, Vijay K. (2004) Worlds of Written Discourse: A Genre-based View. London: Continuum

Blagojević, Savka and Biljana Mišić Ilić (2012) "Interrogatives in English and Serbian academic discourse - a contrastive pragmatic approach". Brno Studies in English 38 (2), 17-36.

Blommaert, Jan (2006) "Sociolinguistic scales". Working Papers in Urban Language and Literacies, Institute of Education, University of London and Ghent University.

Bloor, Meriel, and Thomas Bloor (1993) "How economists modify propositions". In: Henderson, W., Dudley-Evans, A., and Backhouse, R. (eds.), Economics and Language. London: Routledge, 153-169.

Breeze, Ruth (2007) "How personal is this text? Researching writer and reader presence in student writing using Wordsmith Tools". CORELL: Computer Resources for Language Learning $1,14-21$.

Brett, Paul (1994) “A genre analysis of the results section of sociology articles". English for Specific Purposes 13 (1), 47-59.

Brooks, Terrence A. (1984) "Private acts and public objects: an investigation of citer motivations". Journal of the American Society for Information Science 36, 223-229.

Brown, Gillian and George Yule (1983) Discourse Analysis. Cambridge: Cambridge University Press.

Bruffee, Kenneth A. (1986) "Social construction. Language and the authority of knowledge. Abiographical essay". College English 48, 773-779.

Buckingham, Jane and Maurice Nevile (1997) "A model of citation options". ARAL 20 (2), 51-66. 
Canagarajah, Suresh (2002) The Geopolitics of Academic Writing. Pittsburgh, PA: University of Pittsburgh.

Canagarajah, Suresh (1996) "Non-discursive requirements in academic publishing, material resources of peripheral scholars, and the Politics of knowledge production". Written Communication 13 (4), 435-472.

Case, Donald and Georgeann Higgins (2000) "How can I investigate citation behavior? A study of reasons for citing literature in communication". Journal of the American Society for Information Science 51, 635-645.

Chamonikolasová, Jana, Jan Chovanec and Renata Kamenická (eds.) (2012) Brno Studies in English 38 (2).

Chovanec, Jan (2012) "Written academic discourse in English: from local traditions to global outreach". Brno Studies in English 38 (2), 5-16

Cole, James R. (2000) "A short history of the use of citations as a measure of the impact of scientific and scholarly work". In: Cronin, Blaise and Helen Barsky Atkins (eds.) The Web of Knowledge: A Festschrift in Honour of Eugene Garfield. New Jersey: Information Today Inc, 281-300.

Davenport, Elisabeth and Blaise Cronin (2000) "The citation network as a protoreason for representing trust in virtual environments". In: Cronin, Blaise and Helen Barsky Atkins (eds.) The Web of Knowledge: A Festschrift in Honor of Eugene Garfield. New Jersey, Information Today, Inc, 517-534.

Dudley-Evans, Tony (1994) "Genre analysis: an approach to text analysis in ESP". In: Coulthard, Malcolm (ed.) Advances in Written Text Analysis. London: Routledge, 219-228.

Fløttum, Kjersti, Dahl Trine and Trodd Kinn (2006) Academic Voices: Across languages and disciplines. Amsterdam and Philadelphia: John Benjamins Publishing Company.

Flowerdew, John (2001) "Attitudes of journal editors to non-native speaker contributions". TESOL Quarterly 35 (1), 121-149.

Flowerdew, John (2000) "Discourse community, legitimate peripheral participation, and the nonnative-English-speaking scholar". TESOL Quarterly 34 (1), 127-149.

Gosden, Hugh (1992) "Research writing and NNSs: from the editors". Journal of Second Language Writing 1 (2), 123-139.

Groom, Nick (2000) "Attribution and averral revisited. Three perspectives on manifest intertextuality in academic writing". In: Thompson, Paul (ed.) Patterns and Perspectives. Insights into EAP Writing Practice. Reading: The University of Reading, 14-25.

Hamp-Lyons, Liz and Ben Heasley (2006) Study Writing: A Course in Writing Skills for Academic Purposes. Cambridge: Cambridge University Press.

Hanania, Edith and Karima Akhtar (1985) "Verb form and rhetorical function in science writing: a study of MS theses in Biology, Chemistry and Physics". ESP Journal 4 (1), 45-58.

Harwood, Nigel (2005a) “"Nowhere has anybody attempted'... 'In this article I aim to do just that': a corpus-based study of self-promotional $I$ and we in academic writing across four disciplines". Journal of Pragmatics 37, 1207-1231.

Harwood, Nigel (2005b) “'We do not seem to have a theory'...'the theory I present here attempts to fill this gap': inclusive and exclusive pronouns in academic writing”. Applied Linguistics 26 (3): 343-375.

Harwood, Nigel and Gregory Hadley (2004) "Demystifying institutional practices: critical pragmatism and the teaching of academic writing." English for Specific Purposes 23: 355-377.

Hawes, Thomas and Sarah Thomas (1997) "Tense choices in citations". Research in the teaching of English 31 (3), 393-414.

Hill, Susan, Betty Soppelsa and Gregory West (1982) "Teaching ESL students to read and write experimental research papers". TESOL Quarterly 16, 333-347.

Holmes, Richard (1997) "Genre analysis and the social sciences: an investigation of the structure of research article discussion sections in three disciplines". English for Specific Purposes 16 (4), 321-337.

Hopkins, Andy and Tony Dudley-Evans (1988) "A genre-based investigation of the discussion sections in articles and dissertations". English for Specific Purposes 7, 113-121. 
Hyland, Ken (2009) Academic Discourse: English in a Global Context. Continuum London and New York: International Publishing Group.

Hyland, Ken (2005) Metadiscourse. Exploring Interaction in Writing. London and New York: Continuum.

Hyland, Ken (2004) Disciplinary Discourses: Social Interactions in Academic Writing. Ann Arbor: University of Michigan Press.

Hyland, Ken (2002) "Directives: power and engagement in academic writing". Applied Linguistics 23 (2), 215-239.

Hyland, Ken (2001) "Humble servants of the discipline? Self-mention in research articles". English for Specific Purposes 20, 207-226.

Hyland, Ken (2000) Disciplinary Discourses: Social Interactions in Academic Writing. London: Longman.

Hyland, Ken (1999a) "Academic attribution: citation and the construction of disciplinary knowledge". Applied Linguistics 20, 341-367.

Hyland, Ken (1999b) "Disciplinary discourses: writer stance in research articles". In: Candlin, Christopher and Ken Hyland (eds.) Writing: Texts, Processes and Practices. Harlow: Longman, 99-121.

Hyland, Ken (1998) Hedging in Scientific Research Articles. Amsterdam and Philadelphia: John Benjamins.

Ivanic, Roz (1998) Writing and Identity: The Discoursal Construction of Identity in Academic Writing. Amsterdam: John Benjamins.

Kuhn, Thomas (1970) The Structure of Scientific Revolution. Chicago: The University of Chicago Press.

Kuo, Chih-Hua (1999) "The use of personal pronouns: role relationships in scientific journal articles". English for Specific Purposes 18, 121-138.

Latour, Bruno (1987) Science in Action: How to follow scientists and engineers through society. Cambridge, Massachusetts. Harvard University.

Lillis, Theresa and Mary Jane Curry (2010) Academic Writing in a Global Context: The Politics and Practices of Publishing in English. London: Routledge.

Lorés-Sanz, Rosa (2012) "Local disciplines, local cultures: praise and criticism in British and Spanish history book reviews". Brno Studies in English 38 (2), 97-116.

Malášková, Martina (2011) "Hedging in research articles: humanities and social sciences compared”. In: Schmied, Josef (ed.) Academic writing in Europe: Empirical Perspectives. Göttingen: Cuvillier, 143-156.

Martin, James R. (1989) Factual Writing: Exploring and Challenging Social Reality. Oxford: Oxford University Press.

Martin, James R., Christie, Frances and J. Rothery (1987) "Social Processes in education: a reply to Sawyer and Watson (and others)". In: Reid, Ian (ed.) The Place of Genre in Learning: Current Debates. Geelong, Australia: Deakin University Press, 46-57.

Mauranen, Anna (1993) Cultural Differences in Academic Rhetoric. Frankfurt am Main: Lang.

Mur-Dueñas, Pilar (2012) "With regard to L2 academic writing: the use of topicalisers in L1 (English and Spanish) and L2 (English) research articles". Brno Studies in English 38 (2), 117-130.

Myers, Greg (1989) "The Pragmatics of politeness in scientific texts". Applied Linguistics 4, 1-35.

Nkemleke, Daniel (2010) "Cameroonian and foreign scholar's discourse: the rhetoric of conference abstracts". World Englishes 29 (1), 173-191.

Okamura, Akiko (2008) "Citation forms in scientific texts: similarities and differences in L1 \& L2 professional writing". Nordic Journal of English Studies 7 (3), 61-81.

Pho, Phuong Dzung (2008) "Research article abstracts in applied linguistics and educational technology: a study of linguistic realizations of rhetorical structure and authorial stance". Discourse Studies 10 (2), 231-250.

Povolná, Renata (2012) "Causal and contrastive discourse markers in novice academic writing". Brno Studies in English 38 (2), 131-148. 
Pickard, Valerie (1995) “Citing previous writers: what can we say instead of 'say'?" Hong Kong Papers in Linguistics and Language Teaching 18, 89-102.

Salager-Meyer, Françoise (1997) "Scientific multilingualism and the 'lesser' languages". Interciencia 22 (4), 197-201.

Salager-Meyer, Françoise (1992) "A text-type and move analysis study of verb tense and modality distribution in medical English abstracts”. English for Specific Purposes 11 (2), 93-113.

Samraj, Betty (2002) "Introductions in research articles: variations across disciplines". English for Specific Purposes 21 (1), 1-17.

Schmied, Josef (2012) "Academic knowledge presentation in MA theses: from corpus compilation to case studies of disciplinary conventions". Brno Studies in English 38 (2), 149-166.

Shim, Eun-Jung (2005) Explicit writing instruction in higher educational contexts: genre analysis of research article introductions from the English teaching and TESOL quarterly journals. Unpublished doctoral dissertation, University of Minnesota.

Smith, Jr., E.L. (1985) "Functional types of scientific prose". In: James D. Benson and William S. Greaves (eds.), Systemic Perspectives on Discourse 2, Norwood, NJ: Ablex, 241-257.

Shooshtari, Zohre G. and Ali Reza Jalilifar (2010) "Citation and the construction of sub-disciplinary knowledge". The Journal of Teaching Language Skills (JTLS) 2 (1), 45-66.

Swales, John (2004) Research Genres: Exploration and Applications. Cambridge: Cambridge University Press.

Swales, John (1990) Genre Analysis: English in Academic and Research Settings. Cambridge: Cambridge University Press.

Swales, John (1981) Aspects of Article Introductions. Birmingham, UK: The University of Aston, Language Studies Unit.

Tang, Ramona, and John Suganthi (1999) "The 'I' in identity: exploring writer identity in student academic writing through the first person pronoun". English for Specific Purposes 18, 23-39.

Thompson, Paul (2000) "Citation practices in PhD theses". In: Burnard, Lou and Tony McEnery (eds.) Rethinking Language Pedagogy from a Corpus Perspective. Frankfurt: Peter Lang, 99-101.

Thompson, Paul and Christ Tribble (2001) "Looking at citations: using corpora in English for academic purposes". Language Learning \& Technology 5 (3), 91-105.

Thompson, Geoff and Susan Hunston (eds.) (2001) "Evaluation: An introduction". In: Thompson, Geoff and Susan Hunston (eds.) Evaluation in Texts: Authorial Stance and the Construction of Discourse. Oxford: Oxford University Press, 1-27.

Thomas, Sarah, and Thomas, Hawes (1994) "Reporting verbs in medical journal articles". English for Specific Purpose 13 (2), 129-148.

Thompson, Geoff and Yiyun Ye (1991) "Evaluation in the reporting verbs used in academic papers". Applied Linguistics 12, 365-382.

Valero-Garces, Carmen (1996) "Contrastive ESP rhetoric: Metatext in Spanish-English economics texts". ESP Journal 15 (4), 279-294.

Vassileva, Irena (2000) "Commitment and detachment in English and Bulgarian academic writing". ESP Journal 20, 83-102.

Yang, Ruiying, and Desmond Allison (2004) "Research articles in applied linguistics: structures from a functional perspective". English for Specific Purposes 23, 264-279.

Daniel A. Nkemleke holds a PhD in English linguistics (modality in Cameroon English), and has been associate professor at the Ecole Normale Supérieure, University of Yaoundé I, since 2008. He is a research fellow of the Alexander von Humboldt Foundation (2006-2008, 2011, 2013), a Fulbright scholar (2010-2011), and the 2014 Award Winner of the Humboldt Alumni Prize for Innovative Network research Initiative. Daniel has taught linguistics and ELT courses for over a decade in universities in Cameroon and abroad. He is currently director of the corpus of Cameroon English 
project - a database that has been compiled in collaboration with the Department of English at Chemnitz University of Technology, and funded by the Humboldt Foundation. His publications cover a broad range of research interest including descriptive-corpus-based research and issues in methodology and language teaching. His major research interest, however, is academic writing from a corpus-based orientation. During the last five years, he has been investigating academic writing practices in Cameroon English, and his recent book Exploring Academic Writing in Cameroon English (2011) is the outcome of this initiative.

Address: Prof. Daniel A. Nkemleke, English Language and Linguistics, Ecole Normale Supérieure, University of Yaoundé I, Cameroon. [email: nkemlekedan@yahoo.com] 
